\title{
Feedback and Learning Support That Fosters Students' Independent Learning: An Australian Case Study
}

\author{
Tomayess Issa, Curtin University, Australia \\ Theodora Issa, Curtin University, Australia \\ Piet Kommers, University of Twente, Netherlands
}

\begin{abstract}
This paper aims to examine students' reactions to formative (i.e. face to face, audio, wiki and live, email) feedback. This approach is used to improve students' communication and critical-thinking skills and to encourage independent learning. This paper provides empirical evidence from 327 students in three postgraduate units ('IS', 'TI', 'ITS'), and two undergraduate units ('BT2', and 'BT25'). The practical evidence is based on quantitative and qualitative data derived from two sources: informal and formal. The outcomes indicated that students' levels of satisfaction had increased, and students started to learn from their own mistakes to improve the next submission, and their independent learning skills were enhanced in terms of writing, research, using endnote software, teamwork, collaboration and interaction, and oral presentation. Finally, a new model "Foster Student Independent Learning Model (FSILM)" is created to implement fosters students' independent learning in higher education.
\end{abstract}

Keywords: Feedback, Formative, Audio, Australian Higher Education, FSILM

\section{Introduction}

$\mathrm{F}$ eedback in higher education is an essential tool for improving students' assessment tasks, and developing their self-esteem and confidence in their studies as well as in the workplace in the future. To develop these skills among our students, formative and summative feedback approaches have been adopted in postgraduate and undergraduate units within a university in Australia. Formative feedback is an essential aspect of teaching and learning, as lecturers provide regular feedback to the students, ensuring that the knowledge they acquire at the beginning of the semester is applied throughout the semester, and preparing them for future studies and application in real-life scenarios. Additionally, regular feedback prevents students from repeating the same mistakes, and improves their learning behavior and thinking, especially with regards to reporting writing, research and using endnote software. On the other hand, summative feedback informs students about their level of performance on reaching an end point, such as the end of a topic, or specific assessment task, or at the conclusion of the unit. As a result of using both formative and summative feedback, the number of requests for extensions dropped dramatically and the extra time and effort that were put into the planning and organization of cooperative learning tasks was rewarded by an increase in students' levels of satisfaction in the teaching and learning experiences.

New teaching approaches were introduced in these units (Information Technology Seminar (ITS), Information Systems (IS); Technological Infrastructure (TI), Business Technology 20 (BT2) and Business Technology25 (B25) to improve students' communication skills (i.e. research, writing, technology information, critical thinking, reading, debating, and written presentation/oral skills) and to encourage independent learning, and to prepare them for real life in the future. These approaches are: Wiki and audio feedback. Wiki is a website that allows students to add, update, and modify contents on the website. The main purpose of using this tool is to improve students' independent learning, collaboration and interaction skills; while audio feedback will encourage students to learn from their mistakes and improve their next submission by listening to their lecturers' feedback. Integrating assessments in higher education has an enormous influence on students' learning, because via these assessments, the lecturers can

The International Journal of Learning

Volume 19, 2014, www.thelearner.com, ISSN 1447-9494

(c) Common Ground, Tomayess Issa, Theodora Issa, Piet Kommers, All Rights Reserved

Permissions: cg-support@commongroundpublishing.com 
determine whether students have acquired the knowledge presented in the course content, and moreover, students will be encouraged and motivated to commit more fully to their learning (Rust 2001).

These units were developed to raise students' awareness of Sustainability and Green IT, Usability and Human-Computer Interaction, and Networking and Operating Systems, and to prepare them for the workplace in the future, as the majority of these units are relevant to both the academic environment and the business world.

From the business perspective, it was noted that Information Systems practitioners have been eagerly advocating the need for good critical thinking, writing, communication, and oral and written presentation skills in IS graduates. Hence, in the design of curriculum and unit programs, attempts were made to include content and activities that would foster these skills to assist students in their tertiary studies, their future workplace, and life in general. To align with businesses' needs, this study developed motivating and challenging assessments for their postgraduate and undergraduate units by analyzing and evaluating practical real-case studies and journal articles, and later uploading the results to Wiki's tool to be evaluated by the lecturer (the author of this paper) and their peers. Subsequently, the results were presented to the class as either an individual or group presentation. Other means of assessing the students' knowledge and understanding of unit content and objectives included: creating concept maps based on journal articles, report writing, responding to middle- and high-level thinking questions in the mid-semester, and final exams.

This study aims to examine students' reactions to lecturer formative feedback. The findings indicated that this was a win-win strategy since both students, and lecturers are delighted with the feedback and the teaching approaches.

The study findings confirm that integrating universities' graduate attributes with business needs, and providing the necessary and regular formative feedback will develop various communication skills including reading, writing, researching, searching, presenting, and developing endnote software skills, and this improvement will enhance students' self-esteem, self-confidence, and leadership ability. This study makes a contribution to the theoretical and practical implication of feedback in general and higher education in particular by releasing a new model "Foster Student Independent Learning Model (FSILM). This study is organized as follows: formative and summative and technology feedback, research method, research question and assessment tasks, participants, results and discussion, limitations and conclusion.

\section{Formative, Summative and Technology Feedback}

Formative and summative feedback is essential in higher education as a means of supporting students' learning voyage, especially in universities nationally and internationally. These approaches aim to provide information and guidance regarding students' achievements in the class and assessment tasks, and in the live feedback via Wiki, to improve and enhance students' learning and engagement. Jones et al. (2010, 213) define formative assessment as "assessment for learning..., as teachers and students use assessment information to enhance student learning within the classroom and on a daily basis."

Formative feedback considers the evidence of students' present learning and is used by teachers and lecturers to make a judgment and decide whether students need further assistance before making a final submission. The constructive feedback is intended to ascertain whether students are on the right track, and to allow students to learn from their mistakes and prevent future repetitions of the same errors. Furthermore, the adoption of this approach in postgraduate and undergraduate units will improve students' confidence and motivate them to complete the assessment tasks on time, and most importantly, align with the unit objectives and aims (Allen and Bentley 2012; Hancock and Brundage 2010; Lynch, McNamara, and Seery 2012; Wingate 2010). In addition, formative feedback will provide students with various types of feedback to 
improve, and enhance learning and to identify the problems within the assessment in the early stages and to improve their grades. By the same token, Marriott and Lau (2008) state that this approach in teaching will allow students to improve their grades.

Conversely, summative feedback considers the overall feedback regarding students' achievements over a period of time recorded as marks, grades or levels of achievement. Garrison and Ehringhaus $(2007,1)$ state that the purpose of summative feedback is "to determine at a particular point in time what students know and do not know. Many associate summative assessments only with standardized tests such as state assessments, but they are also used at and are an important part of district and classroom programs." In addition, summative feedback provides students with a grade which reflects their level of performances on reaching an end point such as an assessment task, mid-semester test, or final exam. This feedback encourages students to progress in their studies and be better prepared for the workforce in future.

Finally, integrating formative feedback in this study influences students' performance and productivity on the assessment tasks. According to the lecturer, as a result of using formative feedback, the number of requests for extensions dropped dramatically and the extra time and effort that were put into the planning and organization of cooperative learning tasks was rewarded by an increase in students' levels of satisfaction with the teaching and learning experiences.

Feedback to students can be delivered via various platforms from old-style to modern methods including in person, email, audio and Wiki. In the higher education sector, it is essential that feedback be provided via technology because it is flexible and accessible, and encourages students to be enthusiastic about their learning experiences and motivates them to do their best for the final submission. Examples of technology are audio feedback "MP3" and Wiki. Several studies (Hulsmann 2009; Robinson n.d.; Siwinski 2008; Williams 2009) confirm that technology feedback is flexible, easy, accessible, on demand, and provides a personal touch.

Audio feedback (MP3) provides a means of generating informal dialogue between students and lecturers to encourage the learning process. This feedback is related to assessment task submission, including report writing and presentations, and is based on the marking guide provided to the students at the beginning of the semester in relation to writing style, content, references, argument, recommendations and conclusion. The audio feedback took between 5 to 15 minutes as lecturers uploaded it to the Blackboard, and later students were able to access, download and listen to the feedback from any device. This is an interesting and advantageous method as it saves lecturers the time it takes to collect and sort hard copies, add comments and return the hard copies. The use of MP3 audio feedback is flexible and enables students to retrieve and listen to it from anywhere, anytime, and using any device. In addition, the audio feedback was used in these units to capture the new "digital" generation, generation "Y" or the "net" generation since this generation is depending more on the new technology (Gould and Day 2012; Merry and Orsmond 2007 ; Riddle 2010).

On the other hand, feedback via Wiki is less time-consuming and flexible, as this feedback will improve communication and collaboration between students and lecturers, and gives the chance to the lecturers and students to provide live feedback regarding the activities during the class. Several studies (Cowan and Jack 2011; Matheson 2009) have found that using Wiki in teaching and learning will improve teamwork and collaboration between students and lecturers.

Overall, feedback via technology is crucial in the teaching and learning process, especially in higher education, as students will improve the quality of their assessment tasks, learn from their mistakes, and enhance and develop their communications skills including writing, reading, critical thinking and problem solving, research, search and endnote software skills. This type of teaching and feedback allows lecturers to encourage students’ independent learning.

\section{Research Method, Research Question and Assessment Tasks}


This paper aims to examine students' responses to formative, audio and live feedback (using Wiki's tool). This study was carried out with students in postgraduate and undergraduate units in Australia. This study will answer the question 'How can lecturers' formative feedback support and foster students' independent learning in the Australian higher education sector?' To address this question, the researchers adopted two approaches for collecting data: formal feedback and informal feedback from 327 students. The anonymous informal feedback was collected during the period of study (i.e. semester). This feedback is a teaching and learning initiative and is intended to assist the lecturer to improve and enhance the unit before the end of the semester by refining certain aspects of the course to cater for students' needs and improve the methods teaching and learning. The informal feedback was collected via an anonymous on-line system at the university, 'eValuate', used for gathering and reporting students' perceptions regarding their learning outcomes, learning experiences, learning resources, assessments, feedback, workload and overall satisfaction. The assessment tasks for 'IS', 'TI', 'ITS', 'BT2', and 'BT25' are challenging and included a reflective journal, discussion board, mini tests, presentations, and report writing, Wiki contribution, team work assessments, individual assessments, and final exam. These assessments were developed by integrating universities' and business' needs, to assist students in their current studies as well as in the workplace in the future.

\section{Participants}

The study participants comprised 327 postgraduate and undergraduate students (see Table 1). Students were mainly from Australia and Asia (i.e. China, Malaysia, India, Indonesia, Iran, Middle East, Pakistan, and Sri Lanka), and South and North America. This cultural mixture assisted students to learn from each other by sharing knowledge, skills and cultural perspectives and this led to them developing self-esteem, communication skills and self-confidence.

Table 1: Participants - Postgraduate and Undergraduate units - 2009 - 2011

\begin{tabular}{|l|l|}
\hline Year/Semester/unit & Students Enrolled \\
\hline $2009 / 1-I S$ & 20 \\
\hline $2010 / 1-I S$ & 15 \\
\hline $2011 / 1-I S$ & 18 \\
\hline $2009 / 1-T I$ & 25 \\
\hline $2010 / 1-T I$ & 31 \\
\hline $2011 / 1-T I$ & 26 \\
\hline $2010 / 2-I T S$ & 17 \\
\hline $2011 / 2-I T$ & 18 \\
\hline $2009 / 1-B T 2$ & 54 \\
\hline $2009 / 2-B T 2$ & 29 \\
\hline $2009 / 2-B T 25$ & 37 \\
\hline $2010 / 2-B T 2$ & 16 \\
\hline $2010 / 2-B T 25$ & 21 \\
\hline
\end{tabular}

\section{Results}

Integrating formative feedback in postgraduate and undergraduate units is an innovative and novel means of supporting students in the learning process and fostering their independent learning and thinking skills. In this study, the lecturers' teaching confirms that providing feedback to students is essential as it contains detailed, positive and constructive comments so as to improve students' learning process, especially for the second and final submission of tasks. The formative feedback on assessment tasks will assist lecturers to identify students' weaknesses 
and strengths in writing, especially the reflective journals and report writing, as well as the oral presentation.

The results are collected from the informal and formal feedback; the informal feedback was distributed during week 4 of the semester to obtain students' anonymous feedback to teaching, style, assessment tasks, and feedback. The formal feedback is collected by the university at the end of each semester. This feedback is anonymous and provides qualitative and quantitative information in respect to the unit. The success of this approach is evident in the formal student feedback e-VALUate's results which is limited to students' feedback and overall satisfaction (see Table 2). Table 2 confirmed that students are pleased and satisfied with lecturers' feedback, since this feedback encourages them to improve their communication skills, and as well achieve the unit learning outcomes. Furthermore, there are a vast difference between the unit and university average for items 5 and 11 . The average unit is higher than the university, as lecturers' regular feedback provided to improve students' assessment tasks. This feedback as well improved students' professional and personal skills.

Table 2: e-VALUate’s results- Postgraduate and Undergraduate units - 2009 - 2011 (Formal Feedback)

\begin{tabular}{|c|c|c|c|c|c|c|}
\hline Year/Semester/unit & $\begin{array}{l}\text { Students } \\
\text { Enrolled }\end{array}$ & $\begin{array}{l}\text { Responses } \\
\text { Rate }\end{array}$ & $\begin{array}{l}\text { Item } \\
\text { my w } \\
\text { helps } \\
\text { the } \\
\text { outco }\end{array}$ & $\begin{array}{l}\text { eedback on } \\
\text { in this unit } \\
\text { to achieve } \\
\text { learning }\end{array}$ & $\begin{array}{l}\text { Item } \\
\text { satis }\end{array}$ & $\begin{array}{l}\text { Dverall, I am } \\
\text { ith this unit. }\end{array}$ \\
\hline & & & Unit & $\begin{array}{l}\text { University } \\
\text { Average }\end{array}$ & Unit & $\begin{array}{l}\text { University } \\
\text { Average }\end{array}$ \\
\hline $2009 / 1-I S$ & 20 & $55 \%$ & 100 & 77 & 100 & 83 \\
\hline $2010 / 1-I S$ & 15 & $47 \%$ & 100 & 79 & 100 & 83 \\
\hline $2011 / 1-I S$ & 18 & $56 \%$ & 100 & 81 & 100 & 83 \\
\hline $2009 / 1-T I$ & 25 & $24 \%$ & 80 & 76 & 100 & 83 \\
\hline $2010 / 1-T I$ & 31 & $48 \%$ & 100 & 78 & 100 & 83 \\
\hline $2011 / 1-T I$ & 26 & $58 \%$ & 92 & 83 & 92 & 78 \\
\hline $2010 / 2-I T S$ & 17 & $59 \%$ & 90 & 80 & 90 & 84 \\
\hline $2011 / 2-I T S$ & 18 & $72 \%$ & 92 & 78 & 92 & 84 \\
\hline 2009/1 - BT2 & 54 & $54 \%$ & 100 & 76 & 100 & 83 \\
\hline 2009/2-BT2 & 29 & $62 \%$ & 83 & 78 & 88 & 83 \\
\hline $2009 / 2-B T 25$ & 37 & $76 \%$ & 100 & 77 & 100 & 83 \\
\hline $2010 / 2-B T 2$ & 16 & $56 \%$ & 100 & 79 & 100 & 84 \\
\hline $2010 / 2-B T 25$ & 21 & $48 \%$ & 100 & 79 & 100 & 84 \\
\hline
\end{tabular}

Students were very keen, via formal and informal feedback, to share their opinions and perceptions of the lecturer's feedback approach:

"The feedback for this unit is running every week which is useful for improving the user satisfaction. Different activities and non-boring stuff are being offered which is improving motivation. Weekly journal which is improving our communication skills and also enhancing our knowledge about HCI area”.

"My lecturer (First Author) for this unit is the BEST of all the units I am doing this semester. She has been very helpful and always making time to discuss with each of us 
students. She always uses the Blackboard to update us on current information and news on IT and encourage us to share information with other BT students on blackboard”.

"I am happy that the final presentation was based on the final report and that the presentation was 1 week before the submission of the final report. This allows students to have a better understanding on the topic and to know what others are doing without the ability of copying of course. It provides creativity and ideas. It also gives a feedback on the progress of the final report”.

"The most helpful aspect from my point of view is I've read lots of articles and journal during semester in which I became more familiar with professional article and journal and as consequence of these reading I improved my reading and writing skill a lot and learned how to write article professionally" .

"Lecturer (The First Author) was at all times available to answer queries. Moreover, we did some practical exercises that helped us to gain more knowledge of the unit contents"

“* Sustainability is a key issue for every organization around the world so gain a basic knowledge about it is so important and beneficial. * Usage of different learning tools and means like Journal Article analysis, Wiki, case studies, etc. enrich, motivate and increase learning outcome effectiveness. * Create awareness of the commitment everyone has to preserve the planet and improve the quality of life of our peoples while generating long-term profitability for organizations. * Incentive team work through case studies and Wiki tool. * Provide update knowledge about sustainability”

"Helpful aspects: the materials is well-defined, the work-group tools such as Wiki-group is good to learn about the contribution also as a practice for report writing. The material is based on academic point of view supported with journals based on research on the practical world"

"Class is always alive, and fun and active; Exposure and develop good communication skills; the news which teacher says at the start of every session is really informative; Patient in explaining and answering questions, very helpful and encouraging”.

The students' formal and informal feedback given by lecturers assisted students to improve the quality of their assessment tasks. The skills acquired as a result of feedback are necessary for future studies and the workplace. This type of feedback encourages the lecturers to provide further feedback to enhance students' work and to improve their personal and professional skills.

As for the audio feedback (formative live feedback), students added and shared their comments via formal and informal feedback:

"Cool, interesting and so friendly and provide a personal touch; very impressive you can have the tick from my side".

"Keep up the good work; I can listen to your feedback more than once to improve my second submission”.

"I had great affirmation and feedback on my assignment, and I would think that would be the best think lecturer (First Author) could provide to the student, Thanks a lot and this is the first time in my university life that is hearing to an audio file with feedback".

"it's exciting; think this is a great new way to communicate lectures as there is playback available; MP3 is structured cover's points of review, clear and precise" 
Students indicated in the informal feedback that using Wiki tool in this unit assisted them:

"To improve more interaction, collaboration, and teamwork and constrictive comments learning through a modern technique, and this tool is a very good stage to post selfopinions and share ideas with the group members".

“The teacher review really assists me to understand and improve my submission”.

The adoption of feedback mechanisms (i.e. formative, summative) including technology (audio feedback and Wiki) in our teaching approach is intended to enhance students' learning process. To ascertain whether this approach is successful, lecturers need to monitor, check, assess and evaluate students' progress in their learning, especially in the assessments. This approach confirms our study research question, as this can be the scaffold that supports students' independent learning in the current study as well as the workplace in future. With the same token (Allen and Bentley 2012; Evans 2013; Gould and Day 2012; Lynch, McNamara, and Seery 2012; Timmers, Braber-van den Broek, and van den Berg 2013) adopting feedback approaches in higher education will enhance students' knowledge and skills to the unit, as well improve their professional and personal skills.

\section{Discussion}

Implementing formative, audio and live feedback (using Wiki's tool) approaches in our teaching and learning process produced various benefits for the students as well as lecturers. Formative feedback provides instructions and guidelines for completing the units' assessment tasks, especially for students who fall behind. Furthermore, from the lecturers' perspective, regular checking of assignment tasks in progress means that the marking time needed for final submissions will be reduced. Furthermore, the summative feedback is essential in lecturers' teaching, since it will inform students about their level of performance on reaching an end point or the final submission of a specific major assessment task.

Providing feedback via technology (i.e. Audio and Wiki) was used to develop individual learning and to encourage students to learn from their mistakes and improve their next submission by listening to the feedback. As for Wiki, this tool is introduced to improve collaboration and interaction among students to foster their independent learning. The benefits are crucial in developing students' communication and critical-thinking skills, thus fostering independent individuals who will be successful and confident in real-life situations in the future.

By integrating these approaches in their teaching practice, lecturers will have extra time for planning and organizing the implementation of cooperative learning locally and globally, and sharing lecturers' teaching philosophy.

Figure1 summarizes the process of using formative feedback in this study. This figure will assist researchers and academics in the education sector, including higher education, to improve students' communication skills as well independent learning. The Foster Student Independent Learning Model (FSILM) represented in Figure 1 will be implemented and assessed in two different departments in an Australian University in 2013, and later a study will be carried out to examine the relationship between this study and the future study. 


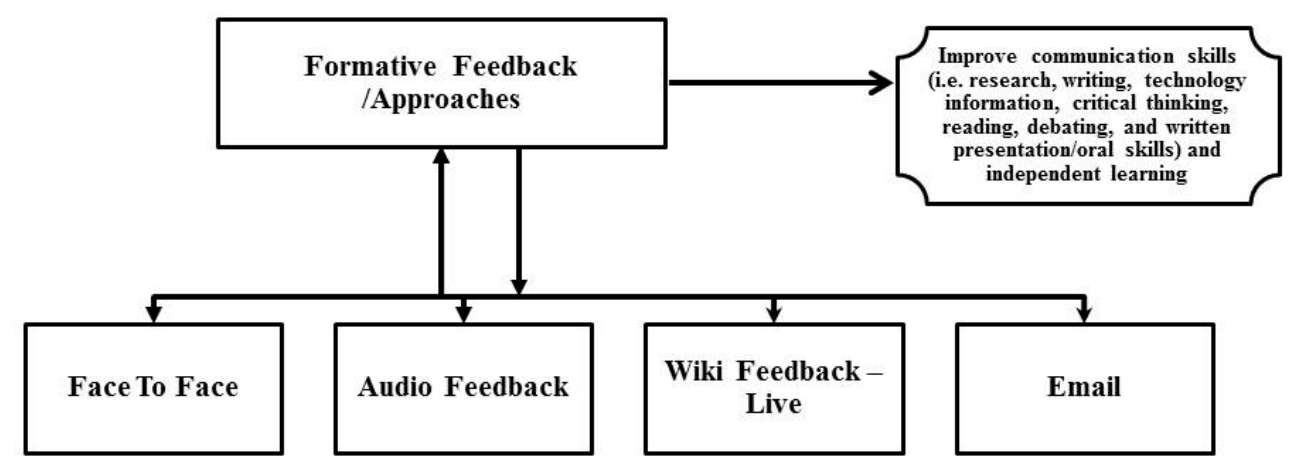

Figure1: Foster Student Independent Learning Model (FSILM) - prepared by the researchers

This study concluded that using formative feedback in higher education will assist students to improve their learning process and encourages independent learning. Regular feedback from the lecturers will enhance the relationship between students and lecturers and improve students' learning in relation to communication skills, and will develop their self-confidence commitment to their studies.

Overall, developing students' skills as independent learners is an essential part of our teaching. Hence, we prepared and organized activities and assessments targeting these skills (problem solving, decision-making, teamwork, writing, research, and oral presentation) which are required for future study and the professional workplace.

\section{Limitation}

The rationale behind this study is to examine students' perspective to lecturer's feedback. This study was based upon a research project undertaken by two lecturers in Australia. In future, further research will be carried out to examine student reaction to Audio Feedback "MP3" and Wiki, and to determine whether technology can assist students to enhance their communication skills, and foster their learning compared with the traditional methods, using large and diverse groups of students in Australia, as well to examine students' influence behind a lecturer summative feedback.

\section{Conclusion}

Providing feedback- formative and summative - in higher education is essential to improve and develop students' communication skills and self-confidence, and this will encourage students to be independent learners. This study was designed to examine this issue by using three sources in a university in Australia. The 327 postgraduate and undergraduate students indicated that formative and summative feedback used together with traditional and modern tools, allowed them to improve and develop their communication skills and learning process by boosting their motivation and inspiration. Overall, based on students' feedback, the study results confirmed the research questions and aims, as students confirmed that via the lecturer's feedback - formative and summative- their learning was improved via the regular feedback from the lecturer. This feedback inspired them to understand the assessments' aims and objectives and prevented them from repeating the same mistakes in future submission. The benefits of using these approaches are essential to the development of students' communications and critical-thinking skills, thus fostering independent individuals who will have a better chance of being successful and confident in future real-life situations. Further research will be carried out to examine students' 
ISSA ET AL.: FEEDBACK AND SUPPORT THAT FOSTERS STUDENTS’ INDEPENDENT LEARNING

attitudes to audio feedback and Wiki tools as well summative feedback, using large and diverse groups of students in Australia. 


\section{REFERENCES}

Allen, Robert , and Steve Bentley. 2012. "Feedback Mechanisms: Efficient and Effective Use of Technology or Waste of Time and Effort " In STEM Annual Conference 2012 London

Cowan, Benjamin R., and Mervyn A. Jack. 2011. "Exploring the Wiki User Experience: The Effects of Training Spaces on Novice User Usability and Anxiety Towards Wiki Editing." Interacting with Computers 23 (2): 117-128. doi: 10.1016/j.intcom.2010.11.002.

Evans, Carol 2013. "Making Sense of Assessment Feedback in Higher Education " Review of Educational Research 83 (1): 70 - 120

Garrison, C, and M Ehringhaus. 2007. Formative and Summative Assessments in the Classroom. Accessed 14 Sept 2012, http://ccti.colfinder.org/sites/default/files/guyana/resources/TL/TL\%20M02U03\%20doc s/Formative\%20and\%20Summative\%20Assessment\%20in\%20the\%20Classroom.pdf.

Gould, Jill, and Pat Day. 2012. "Hearing You Loud and Clear: Student Perspectives of Audio Feedback in Higher Education." Assessment \& Evaluation in Higher Education: 1-13. doi: 10.1080/02602938.2012.660131.

Hancock, Adrienne, and S Brundage. 2010. "Formative Feedback, Rubrics, and Assessment of Professional Competency through a Speech-Language Pathology Graduate Program." Journal of Allied Health 39 (2): 110 -119.

Hulsmann, T. 2009. "Podcasting for Learning in Universities." Distance Education 30 (3): 451458. http://www.informaworld.com/smpp/content $\sim$ content $=\mathrm{a} 915714799 \sim \mathrm{db}=\mathrm{all} \sim$ jump type $=$ rss.

Jones, A., B. Cowie, and J. Moreland. 2010. "Assessment in Schools - Technology Education and Ict." In International Encyclopedia of Education (Third Edition), eds Peterson Editors-in-Chief: Penelope, Baker Eva, Eva Baker Barry McGawA2 - Editors-inChief: Penelope Peterson and McGaw Barry, 311-315. Oxford: Elsevier.

Lynch, Raymond , Particia Mannix McNamara, and Niall Seery. 2012. "Promoting Deep Learning in a Teacher Education Programme through Self-and Peer-Assessment and Feedback " European Journal of Information Systems 35 (2): 179 - 197.

Marriott, Pru, and Alice Lau. 2008. "The Use of on-Line Summative Assessment in an Undergraduate Financial Accounting Course." Journal of Accounting Education 26 (2): 73-90. doi: 10.1016/j.jaccedu.2008.02.001.

Matheson, James 2009. Benefits of Using a Wiki Accessed 15 Sept 2012 http://wiki.customware.net/repository/display/wwyw/Benefits+of+using+a+wiki.

Merry, S, and P Orsmond. 2007 "Students' Responses to Academic Feedback Provided Via Mp3 Audio Files." In The Science Learning and Teaching Conference 100 - 114.

Riddle, Johanne. 2010. "Podcasting in the Classroom: A Sound Success." MultiMedia and Internet@schools 17 (1): 23 -26.

Robinson, L. n.d. "Podcasting - an Emerging Technology in Business Education." www.sbea.us/Podcasting.ppt.

Rust, C. 2001. A Briefing on the Assessment of Large Groups. York

Siwinski, C. 2008. Podcasting: A New Genre Exciting Students. Accessed 16 Sept 2012, http://www.ga.k12.pa.us/curtech/podcasting08/podcasting08_files/podcasting08.ppt.

Timmers, Caroline F., Jannie Braber-van den Broek, and Stéphanie M. van den Berg. 2013. "Motivational Beliefs, Student Effort, and Feedback Behaviour in Computer-Based Formative Assessment." Computers and Education 60 (1): 25 - 31. doi: 10.1016/j.compedu.2012.07.007.

Williams, J. 2009. An Introduction to the Echosystem. Accessed 16 Sept 2012, http://www.canberra.edu.au/tlc/asd/attachments/pdf3/echo360-Presentation.pdf. 
Wingate, Ursula. 2010. "The Impact of Formative Feedback on the Development of Academic Writing " Assessment \& Evaluation in Higher Education 35 (5): 519 - 533.

\section{ABOUT THE AUTHORS}

Dr. Tomayess Issa: Tomayess Issa is a senior lecturer at the School of Information Systems at Curtin University, Australia. In addition, she is a postgraduate course leader and postgraduate online coordinator. Tomayess has vast experience in Australian tertiary education, teaching usability and human computer interaction, social network, sustainability and green it, networking and operating systems. Tomayess completed her doctoral research in web development and human factors. Currently, Tomayess is teaching undergraduate and postgraduate units at the School of Information Systems focusing mainly on usability, human computer interaction, web 2.0, web 3.0, sustainability and green IT, cloud computing, networking, and operating systems.

Dr. Theodora Issa: Dr. Theodora Issa is the unit coordinator and lecturer at the Curtin Business School, Curtin University, Australia. Theodora holds a Master's degree in business administration, electronic commerce, and management research. Theodora's PhD thesis was on ethical mindsets, spirituality, and aesthetics. Theodora's research interests include teaching, online teaching and learning, ethical mindsets, ethical climate, spirituality, aesthetic judgment, sustainable business development and ethical strategies, which ignited her interest in Green IT and cloud-computing

Dr. Piet Kommers: Faculty of Behavioral Sciences, University of Twente, Netherlands. 
